\title{
DESIGN EXPERT SUPPORTED FORMULATION DEVELOPMENT, MATHEMATICAL OPTIMIZATION AND PREDICTABILITY STUDY OF FLOATING TABLETS OF BISOPROLOL FUMARATE
}

\author{
SHAIKH SHAOOR AHMAD ${ }^{2}$, SHAIKH SIRAJ N. ${ }^{*}$, PATEL M. SIDDIK ${ }^{1}$, KHALIFA MAHMADASIF YUNUS ${ }^{1}$, MAKRANI \\ SHAHARUKH I. ${ }^{1}$, SIDDIQI HIFZURRAHMAN MD A. ${ }^{3}$, SHAIKH SALMAN ISMAIL ${ }^{4}$
}

${ }^{1}$ Ali-Allana College of Pharmacy Akkalkuwa Dist, Nandurbar, Maharashtra, India, 425415, 2Shree Swami Samarth Ayurvedic Pharmacy (Allopathic Division) Ltd. Jalgaon 425001, Maharashtra, India, 3Department of Pharmaceutics, Jamia College of Pharmacy Akkalkuwa, Nandurbar, 425415, Maharashtra, India, ${ }^{4}$ Pell Tech Health Care Pvt Ltd. Mumbai Maharashtra, India Email: sirajsk1234@gmail.com

Received: 02 Dec 2020, Revised and Accepted: 05 Feb 2021

\section{ABSTRACT}

Objective: Focus of the study was to formulate Design expert Software assisted floating tablet of Bisoprolol Fumarate. Bisoprolol Fumarate is a Beta adrenergic blocking agent, used to treat cardiac diseases favorable characters to be formulated as sustained release Gastro retentive floating tablets.

Methods: Floating Tablets of Bisoprolol Fumarate were prepared by using polymers such as Polyox N 12 K and Carbapol 940 P. Formulations were prepared by using direct compression method and evaluated for various parameters like Hradness, thickness, weight variations, Floating lag time Total floating time,\% drug release and Stability Study etc.

Results: FTIR spectroscopic study indicates no drug-excipients interaction in the prepared formulations. Hardness or crushing strength of the tablets of all the formulation was found between 5.8 and $6.5 \mathrm{~kg} / \mathrm{cm}^{2}$. Floating lag time of all batches is in range of $1.18 \pm 2.0$ to $2.43 \pm 1.6$ (minutes). All other parameters of all batches are within an acceptable range. The polymer Carbopol $940 \mathrm{P}$ had the significant negative effect of on the floating lag times. The In vitro dissolution profiles of optimized A3 Floating formulation of Bisoprolol Fumarate were found to sustain drug release $99.25 \%$ up to $12 \mathrm{~h}$ with floating lag time of $1.45 \mathrm{~min}$; Designed formulation was stable after Stability study. Optimization study was carried out by using $3^{2}$ factorial designs to fabricate formulations.

Conclusion: It can be conclude that reproducible results of various parameters in this developed formulation can easily scale up. Furthermore designed formulation will be very effective for controlling blood pressure.

Keywords: Software Supported, Bisoprolol Fumarate, Carbapol 940 P, Floating, Direct compression, Floating lag time, Characterization

(C) 2021 The Authors. Published by Innovare Academic Sciences Pvt Ltd. This is an open access article under the CC BY license (https://creativecommons.org/licenses/by/4.0/) DOI: https://dx.doi.org/10.22159/ijap.2021v13i2.40433. Journal homepage: https://innovareacademics.in/journals/index.php/ijap

\section{INTRODUCTION}

Over the past few decades, gastric retention has received immense popularity in segment of oral drug delivery [1]. Numerous Gastroretentive drug delivery systems (GRDDS) have been designed to retain drug in the gastric region for prolonged time ${ }^{2}$ and release incorporated drug [2]. And thereby enable sustained and prolonged input of the drug to the upper part of the GIT thus leading its optimal bioavailability [3].

Reported techniques for fabrication of GRDDS are Floating [4-7]., Sedimentation [8-11]., Mucoadhesion [12, 13]., Swelling and expanding system [14]., modified shape [15]. etc. Techniques which shown clinical evidence for prolonged gastric residence time is floating, swelling and Mucoadhesion [16, 17].

Floating dosage drug delivery system (FDDS) have the sufficient buoyancy to float over the gastric contents for a longer time and hence it increases bioavailability of drugs which are primly absorbed in stomach [18-23].

Mucoadhesive system is capable to adhere mucous membrane that prevents their passage through the pylorus and the dosage forms are retained in the stomach for a longer period of time [24-26].

Hypertension it is defined as abnormally high blood pressure (more than $120 / 80 \mathrm{~mm}$ of $\mathrm{Hg}$ ) in the arteries. It is generally symptoms less, but increases the risk of various other CVS diseases like Stroke, Heart Attack, and non-CVS diseases like renal damage, end-stage renal failure [27].

Moreover Bisoprolol fumarate ((RS)-1-\{4-[(2-isopropoxyethoxy) methyl] phenoxy\}-3-(Isopropylamino) propan-2-ol) is a beta adrenergic blocking agent, used to treat cardiac disease [28]. For a drug that have absorption window in the stomach, prolonging the gastric residence time may significantly enhance the extent of its absorption [28, 29].

So aim of present research work effervescent approach based Floating tablets of Bisoprolol were fabricated by using various polymers such as Polyox N $12 \mathrm{~K}$ and Carbapol $940 \mathrm{P}$ with the help of Design expert Software.

\section{MATERIALS AND METHODS}

\section{Materials}

Bisoprolol Fumarate was obtained as a gift sample from Mehta API Pvt. Ltd. Tarapur Biosar, India. Polyethylene oxide (Polyox $12 \mathrm{~K}$ ) was gifts from Colorcon Asia Pvt. Ltd. Goa, India. Carbopol 940P, Sodium Bicarbonate, Citric Acid,PVP K-30,Talc, Magnesium stearate, Dicalcium Phosphate were purchased from Research Lab Fine Chem. Ltd. Mumbai India.

\section{Methods}

Drug-excipient compatibility

The Infrared Spectra of pure Bisoprolol Fumarate, optimized formulations were recorded between 600 and $4000 \mathrm{~cm}^{-1}$ by FT-IR Spectrometer using $\mathrm{KBr}$ pellet technique to find out any possible drug-excipient interaction.

Fabrication of floating tablets of bisoprolol fumarate

All the floating tablets were fabricated by using the direct compression technique. Drug and Polyox N 12 K,Carbopol 940, PVP K-30 and Dicalcium Phosphate were blended homogeneously with the help of mortar. Blended mixture was passed through Sieve 60, 
finally Sodium bicarbonate and magnesium stearate,talc was added and blended. The homogeneously blended mixture was compressed. The final blend was then compressed into tablets on a 9-station rotary tablet machine (Rimek Mini Press-II, Karnavati, Ahemadabad,India) using 9-mm round plain punches. The detailed composition of formulations is presented in table $3[28,29]$.

\section{Optimization of the formulation parameters and the processing}

Concentrations of polyoxyethylene oxide polyox N $12 \mathrm{~K}$ (X1) and concentration Carbopol 940 P (X2) were selected as independent variables, whereas gastro retentive parameters like floating lag time (Y1) and \% Dug release at $10 \mathrm{~h}$ (Y2) were selected as dependent variables as shown in table 1 and 2 [30].

Table 1: Layout of batches by $3^{2}$ full factorial designs

\begin{tabular}{lll}
\hline Batch No. & X1 & X2 \\
\hline A1 & -1 & -1 \\
A2 & -1 & 0 \\
A3 & -1 & +1 \\
A4 & 0 & -1 \\
A5 & 0 & 0 \\
A6 & 0 & +1 \\
A7 & +1 & -1 \\
A8 & +1 & 0 \\
A9 & +1 & +1 \\
\hline
\end{tabular}

Table 2: Translation of coded value in an actual unit

\begin{tabular}{lll}
\hline Coded value & Polyox N12 K (X1) & Carbopol 940 P(X2) \\
\hline-1 & 70 & 15 \\
0 & 90 & 20 \\
+1 & 110 & 25 \\
\hline
\end{tabular}

\section{Characterization floating tablets of bisoprolol fumarate}

\section{Shape and appearance}

All formulations were prepared well and select randomly and picked from each batch examined under the lens for shape and in the presence of light for color.

\section{Tablet hardness}

Hardness of the tablets was measured using a Monsanto hardness tester. The hardness expressed in $\mathrm{kg} / \mathrm{cm} 2$. For each batch three tablets were tested. This tester applies force to the tablet diametrically [31].

\section{Thickness}

Five tablets of the formulation were picked randomly and thickness was measured individually using a venire caliper.

\section{Friability}

For each batch, 20 tablets were weighed and placed in the Roche friabilator and apparatus was rotated at $25 \mathrm{rpm}$ for $4 \mathrm{~min}$. After revolutions, the tablets were de-dusted and weighed again. The percentage friability was measured using formula,

$$
W t / W)\} \times 100
$$

Where, $\% \mathrm{~F}=$ Friability in percentage $\mathrm{W}=$ Initial weight of tablets Wt. $=$ Weight of tablets after revolution.

Friability below $1 \%$ was considered acceptable

\section{Tablet weight variation}

Weight variation was determined as per I. P. Results are expressed as mean values \pm SD. 20 tablets were randomly selected from each batch and individually weighed. The average weight and standard deviation of 20 tablets was calculated. The batch passes the test for weight variation test if not more than two of the individual tablet weight deviates from the average weight [31].

Table 3: Composition of optimization batches

\begin{tabular}{|c|c|c|c|c|c|c|c|c|c|}
\hline \multirow[t]{2}{*}{ Ingredients (mg) } & \multicolumn{9}{|c|}{ Formulation batch code } \\
\hline & A1 & A2 & A3 & A4 & A5 & A6 & A7 & $\mathbf{A 8}$ & A9 \\
\hline Bisoprolol Fumarate & 20 & 20 & 20 & 20 & 20 & 20 & 20 & 20 & 20 \\
\hline Polyox N12 K & 70 & 70 & 70 & 90 & 90 & 90 & 110 & 110 & 110 \\
\hline Carbopol $940 \mathrm{P}$ & 15 & 20 & 25 & 15 & 20 & 25 & 15 & 20 & 25 \\
\hline PVP K-30 & 10 & 10 & 10 & 10 & 10 & 10 & 10 & 10 & 10 \\
\hline Sodium Bicarbonate & 45 & 45 & 45 & 45 & 45 & 45 & 45 & 45 & 45 \\
\hline Citric Acid & 15 & 15 & 15 & 15 & 15 & 15 & 15 & 15 & 15 \\
\hline Talc & 5 & 5 & 5 & 5 & 5 & 5 & 5 & 5 & 5 \\
\hline Magnesium Stearate & 5 & 5 & 5 & 5 & 5 & 5 & 5 & 5 & 5 \\
\hline Dicalcium Phosphate & QS & QS & QS & QS & QS & QS & QS & QS & QS \\
\hline Total weight (mg) & 260 & 260 & 260 & 260 & 260 & 260 & 260 & 260 & 260 \\
\hline
\end{tabular}

*All the values are mean \pm SD of three determinations, $Q S=$ Quantity Sufficient

\section{Drug content uniformity}

5 Tablets are weighed and powdered, from it average weight equivalent to dose of drug is weighed and added into $100 \mathrm{ml}$ volumetric flask; this powder is dissolved in $0.1 \mathrm{~N} \mathrm{HCl}$ and sonicated for $10 \mathrm{~min}$. From the above solution, $1 \mathrm{ml}$ is taken and diluted to 10 $\mathrm{ml}$ with $0.1 \mathrm{~N} \mathrm{HCl}$ to get concentration of $50 \mu \mathrm{g} / \mathrm{ml}$. Then this solution is analyzed on UV Spectrophotometer using $222.0 \mathrm{~nm}$ wavelengths. Each sample was analyzed in triplicate.

\section{In vitro buoyancy study}

The in vitro buoyancy was determined by floating lag time (FLT) and total floating time (TFT). The time required for the tablet to rise to the surface and float was determined as floating lag time. The tablets were placed in a glass beaker, containing $100 \mathrm{ml}$ of $0.1 \mathrm{~N} \mathrm{HCl}$ as a medium, maintained in a water bath at $37 \pm 0.5^{\circ} \mathrm{C}$. Floating lag time and total floating duration were determined [32].

\section{Water uptake studies}

For each formulation batch, one tablet was weighed and placed in a beaker containing $200 \mathrm{ml}$ of $0.1 \mathrm{~N} \mathrm{HCl}$. After each interval the tablet was removed from beaker and weighed again up to $12 \mathrm{~h}$. The swelling index study was performed in in triplicate and it calculated by using following formula.

$$
\text { (Swelling index }(\text { S. I })=\{(\text { wt-wo }) / \text { wo }\} \times 100 \ldots . .(2)
$$

Where, S. I. = Swelling index

$\mathrm{Wt} .=$ Weight of tablet at time $\mathrm{t}$

Wo $=$ Weight of tablet before placing in the Beaker [32].

\section{In vitro drug release studies}

The release rate of Bisoprolol Fumarate from floating-mucoadhesive tablets was determined using USP dissolution testing apparatus II (Paddle type). The dissolution test was performed by using $900 \mathrm{ml}$ of $0.1 \mathrm{~N} \mathrm{HCl}$ as a dissolution media having pH 1.2 as per USP guidelines, at $37 \pm 0.5{ }^{\circ} \mathrm{C}$ and $75 \mathrm{rpm} / \mathrm{min}$. A sample $(1 \mathrm{ml})$ of the solution was withdrawn from the dissolution apparatus hourly for $12 \mathrm{~h}$, and the sample is replaced with fresh dissolution medium. The samples were passed through what man filter paper and the absorbance of these solutions was measured at $222 \mathrm{~nm}$ [33]. 


\section{Stability study}

Stability studies were carried out at room temperature $40 \pm 20^{\circ} \mathrm{C}$ and $75 \pm 5 \% \mathrm{RH}$ for a specific time period up to 3 Mo for selected formulations. For stability study, the tablets were sealed in Aluminium packaging coated inside with polyethylene. These sample containers were placed in Stability chamber and various parameters were studied [34].

\section{RESULTS AND DISCUSSION}

\section{FT-IR studies for drug-excipient compatibility}

FTIR analysis was performed to authenticate the major functional groups present in formulation blend. Compatibility studies of pure drug Bisoprolol Fumarate with polymers were carried out prior to the preparation of tablets. I. R spectra of pure drug Bisoprolol Fumarate, and that of with polymers were obtained, which are shown in fig. 1 to fig. 2. All the characteristic peaks of Bisoprolol fumarate were present in spectra of formulation blend thus indicating compatibility between drugs. It shows that there was no significant change in the chemical integrity of the drug.

\section{Physical properties of the compressed floating tablet systems}

Floating tablets of Bisoprolol Fumarate were prepared by direct compression method using various polymers such as Polyox N $12 \mathrm{~K}$ and Carbapol 940 P. The results of the physical characteristics of floating tablets are shown in table 4.

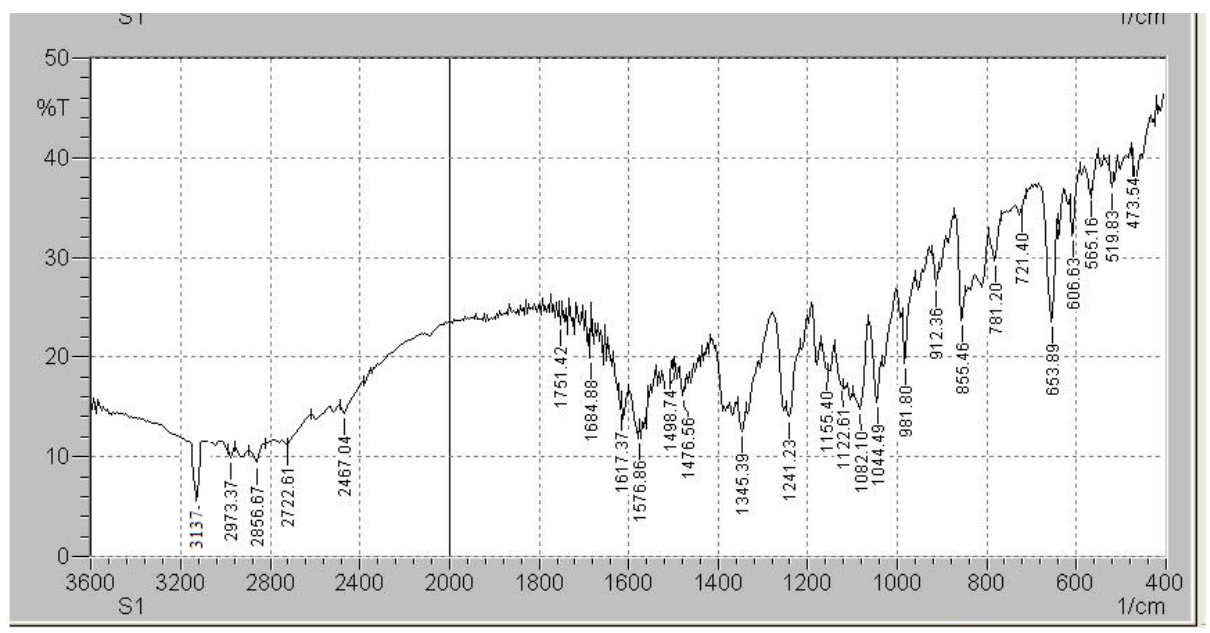

Fig. 1: FT-IR spectra of bisoprolol fumarate, the IR spectrum of pure drug was found to be similar to the reference standard IR Spectrum of Bisoprolol fumarate given in Indian pharmacopoeia

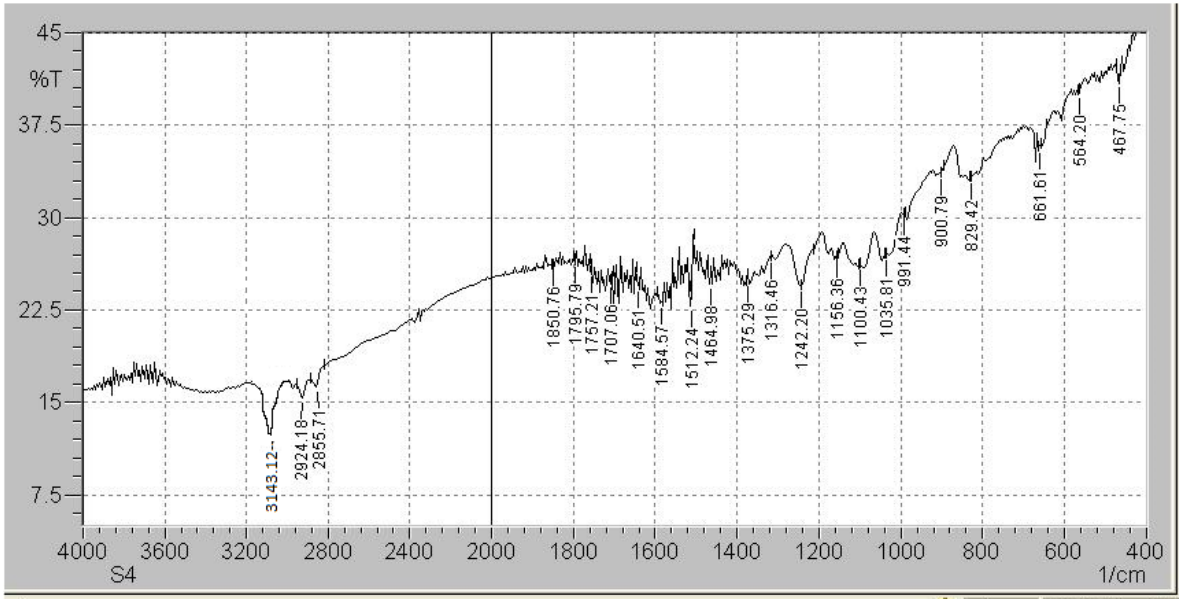

Fig. 2: FT-IR spectra of formulation blend

Table 4: Physical properties of the compressed floating tablet systems

\begin{tabular}{|c|c|c|c|c|c|}
\hline Formulations & Hardness $\left(\mathrm{kg} / \mathrm{cm}^{2}\right)$ & Thickness (mm) & Friability (\%) & Weight variation (mg) & Drug content (\%) \\
\hline A1 & 5.9 & $4.5 \pm 0.04$ & $0.52 \pm 0.11$ & $260 \pm 0.25$ & $98.64 \pm 2.45$ \\
\hline A2 & 5.8 & $4.5 \pm 0.02$ & $0.42 \pm 0.01$ & $260 \pm 1.25$ & $98.85 \pm 1.80$ \\
\hline A3 & 5.9 & $4.7 \pm 0.08$ & $0.41 \pm 0.00$ & $257 \pm 1.75$ & $99.05 \pm 2.51$ \\
\hline A4 & 6.0 & $4.3 \pm 0.07$ & $0.50 \pm 0.09$ & $261 \pm 1.25$ & $98.75 \pm 3.66$ \\
\hline A5 & 6.2 & $4.2 \pm 0.01$ & $0.48 \pm 0.07$ & $253 \pm 0.25$ & $99.10 \pm 1.82$ \\
\hline A6 & 6.5 & $4.8 \pm 0.09$ & $0.43 \pm 0.02$ & $255 \pm 2.25$ & $97.95 \pm 2.17$ \\
\hline A7 & 6.3 & $4.6 \pm 0.02$ & $0.41 \pm 0.00$ & $256 \pm 2.75$ & $99.23 \pm 3.20$ \\
\hline A8 & 6.4 & $4.4 \pm 0.02$ & $0.45 \pm 0.04$ & $263 \pm 1.75$ & $98.86 \pm 2.12$ \\
\hline A9 & 6.5 & $4.5 \pm 0.06$ & $0.47 \pm 0.06$ & $261 \pm 2.75$ & $97.73 \pm 2.14$ \\
\hline
\end{tabular}

*All the values are mean \pm SD of three determinations 
All Formulations were prepared well and select randomly and picked from each batch examined under lens for shape and in presence of light for color. Tablets showed standard concave surfaces with circular shape. Tablets were white in color. Thickness of the tablets was measured using calibrated dial calipers by picking three tablets randomly from all the batches. The physical evaluation of the tablets revealed uniform thickness. All the tablets passed the weight variation test, i.e., average percentage weight variation was found within the pharmacopoeia limits of $\pm 10 \%$. Hardness or crushing strength of the tablets of all the formulation was found between 5.8 and $6.5 \mathrm{~kg} / \mathrm{cm}$. Low friability values (below $0.41 \%$ ) across all formulations indicated that the tablets possess good mechanical strength. The obtained results were found to be well within the approved range $(<1 \%)$ in all the designed formulations. The drug content uniformity was examined as per I. P specification. All the batches of tablets were found to comply with uniformity of content test. The drug content uniformity studies revealed that drug content between $97.73 \pm 2.14$ and $99.23 \pm 3.20 \%$ is acceptable [35].

\section{Effect of independent variables on floating lag time (Y1)}

Floating tablets is usually fabricated in such a way that its density becomes low enabling it to float over gastric fluid. One of the crucial factor in designing of floating drug delivery is floating lag time. Sodium bicarbonate is responsible for the buoyancy of the tablets due to the formation of $\mathrm{CO} 2$, when it came in contact with SGF pH 1.2. The observed results of floating lag times [35] and total floating time of all formulations are displayed in table 5. Buoyancy study of batches A1 to A9 shows good buoyancy characteristics. Total floating time of all the formulation was determined.

Table 5: In vitro buoyancy study of optimized batches

\begin{tabular}{lll}
\hline Formulation codes & Floating lag time (min) & Total FLT hours \\
\hline A1 & $2.30 \pm 1.24$ & $>12$ \\
A2 & $2.43 \pm 1.6$ & $>12$ \\
A3 & $1.45 \pm 1.8$ & $>12$ \\
A4 & $2.24 \pm 1.7$ & $>12$ \\
A5 & $2.1 \pm 1.4$ & $>12$ \\
A6 & $2.14 \pm 2.0$ & $>12$ \\
A7 & $1.20 \pm 1.5$ & $>12$ \\
A8 & $1.20 \pm 1.2$ & $>12$ \\
A9 & $1.18 \pm 2.0$ & $>12$ \\
\hline
\end{tabular}

*All the values are mean \pm SD of three determinations

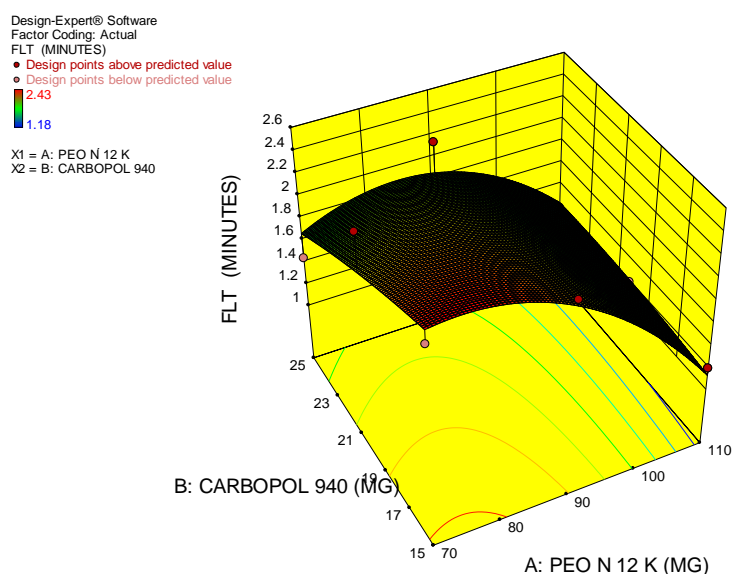

Fig. 3: A response surface plot showing effect of concentration of independent variables on the floating lag time

To evaluate the effect of independent variables on floating lag time design, expert software was used. A quadratic Model model was suggested for floating lag time because of the significant pvalue(0.0045). From response surface plot and contour plot is cited in fig. 4 and fig. 5 . it can be observed that both polymers polyethylene
Oxide (PEO)(X1) and Carbopol $940 \mathrm{P}$ (X2) have a significant effect on floating lag time. Moreover, the effect of the polymer Carbopol $940 \mathrm{P}$ had significantnegative effect of on the floating lag times means increase Carbopol 940 amount (X2) will be accompanied by significant reduction in the floating lag times it might be due to the hydrophilic nature of Carbopol 940P produces faster medium penetration rate, and thus, shorter time for gel layer formation these findings are similar to what has been reported by [36].

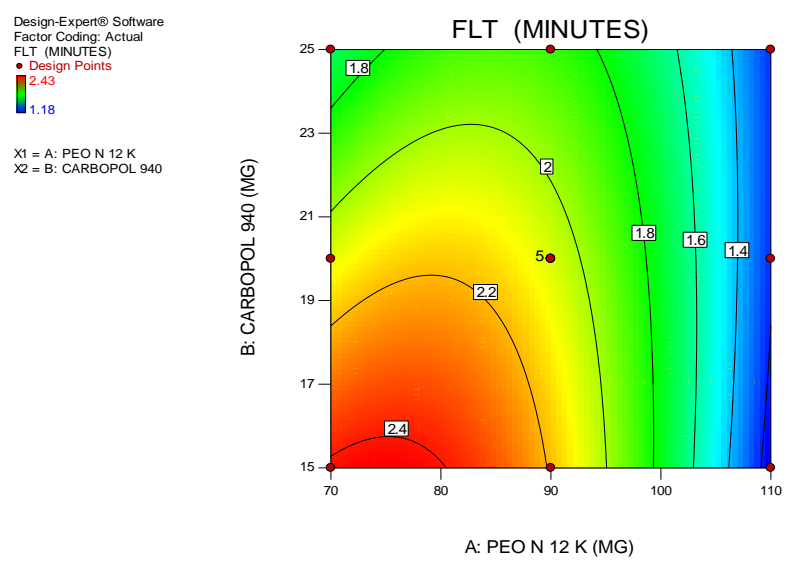

Fig. 4: A counter plot showing relationship between various levels of independent variables to gain fixed value of floating lag time

Mathematical relationship in the form of polynomial equation for the measured response floating lag time was obtained and given in equation 3 below. Positive sign of $X$ in the regression equation indicated agonistic effect and negative sign of $X$ in the regression equation indicated antagonistic effect of independent variables on response.

Final Equation in Terms of Coded Factors: FLT $=+2.07-0.43 * \mathrm{~A}-0.16^{*}$ $\mathrm{B}+0.21 * \mathrm{~A} * \mathrm{~B}-0.41 * \mathrm{~A} 2-0.038 * \mathrm{~B} 2$ (3)

\section{Water uptake study}

The swelling behaviour of of Bisoprolol fumarate floating throughout a period of $12 \mathrm{~h}$ is graphically illustrated in fig. 6 . Swelling of tablet excipients particles involves the absorption of a liquid resulting in an increase in weight and volume. The swelling index of the tablets increases with an increase in the polymer concentration, specially and Carbopol $940 \mathrm{P}$, since the hydration of such functional groups leads to solvent penetration inside the polymer matrix resulting in polymer network expansion and arrangement of the polymer chains. When erosion of polymer dominates over water sorption hence the reduction in tablet weight occurs because of constant due to constant erosion of matrix [37]

The Swelling Index of optimized batches is shown in fig. 5.

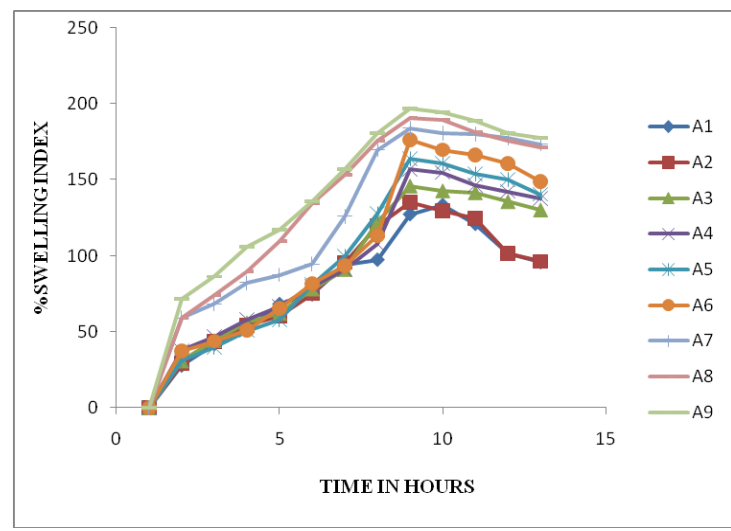

Fig. 5: \% Swelling index of optimized batches 
Polyox is a nonionic, highly swelling hydrophilic polymer absorbing 7 times its initial weight of water. The swelling ability of the tablets could be attributed to the existence of hydrophilic moieties on both Polyox N 12K and Carbopol 940 P [38, 39].

\section{Effect of independent variables on In vitro drug release (Y2)}

Design-Expert was used to determine the degree of effect of each polymer on the percent of drug release [40] is cited in fig. 6 and fig. 7

The In vitro drug release studies of factorial batches were carried out using USP Type II dissolution assembly.

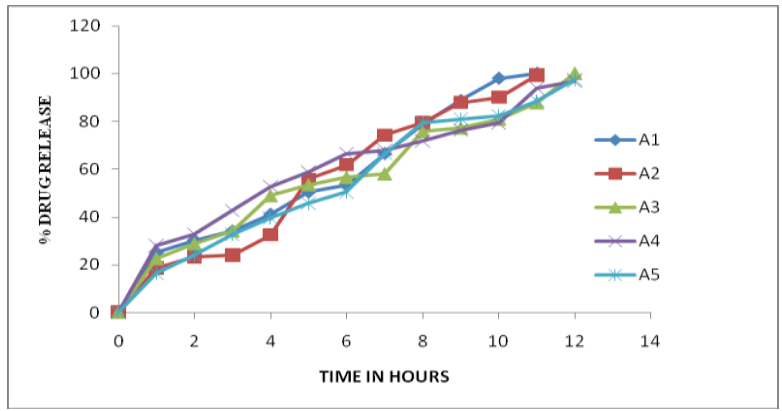

Fig. 6: \% Drug release in graphical presentation: (A1 to A5)

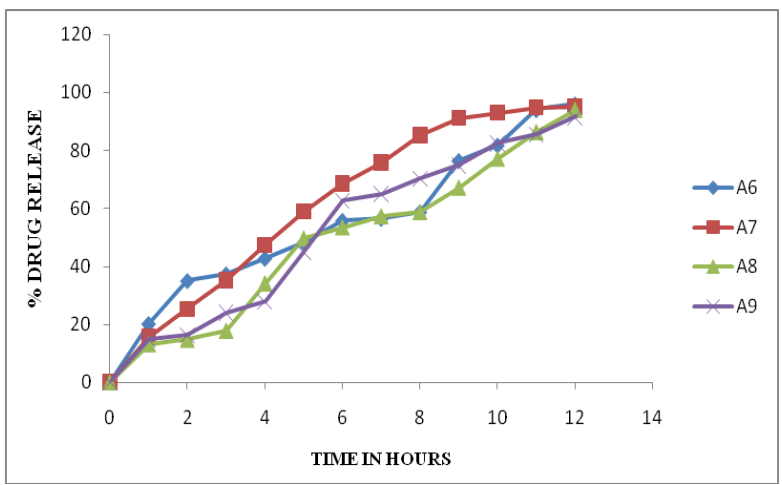

Fig. 7: \% Drug release in graphical presentation: (A6 toA9)

Mathematical relationship in the form of polynomial equation for the measured response (\%CDR at $10 \mathrm{~h}$ ) was obtained and given in the equation below 4 .

$$
\% \mathrm{DR}=+85.75-4.7^{*} \mathrm{~A}-2.23^{*} \mathrm{~B}+4.63^{*} \mathrm{~A} * \mathrm{~B}
$$

The response surface and contour plots presenting the effects of the independent variables on drug release are illustrated in fig. 9 and 10. It is clear from these fig. that both polymers decrease the percent of drug release. In addition, Eqs. (4) Show that Carbopol $940 \mathrm{P}$ has a more pronounced effect on the percent of drug released. This is because of hydrophobic characteristics of the Carbopol 940 P. The decreased effect of Carbopol at higher amounts could be possibly due the saturation of interstitial space between the swollen gel particles. Combination of the prolonged gastric residence time and sustained drug release is expected to improve therapeutic effect and patient's compliance [40].

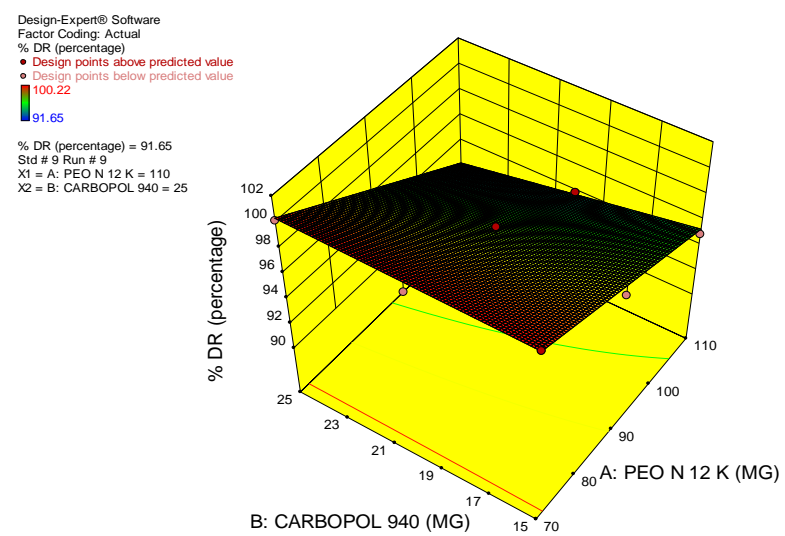

Fig. 8: A response surface plot showing effect of concentration of independent variables on the \% drug release
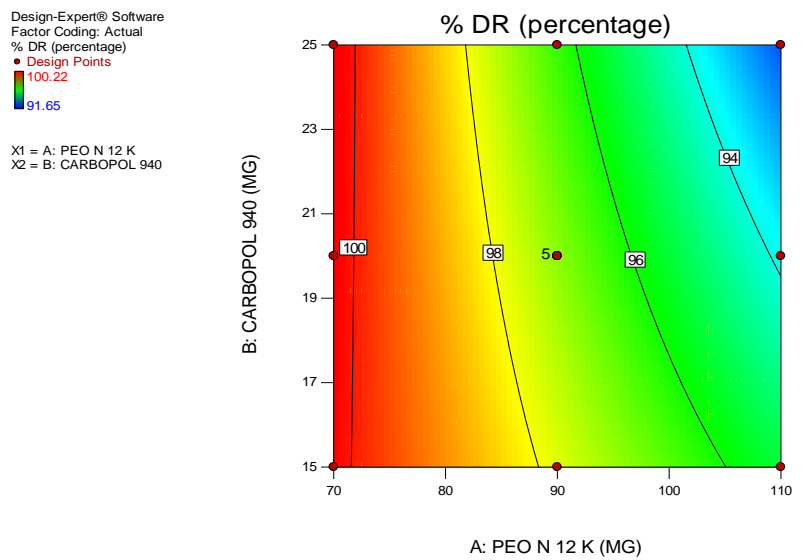

Fig. 9: A counterplot of showing the relationship between various levels of independent variables to gain fixed value of $\%$ drug release

Optimization data analysis for the floating mucoadhesive tablets Responses observed for nine formulations were fitted to Design Expert Software. All values of $\mathrm{R}^{2}$, degree of freedom and \% coefficient of variance etc were shown in table 6. Results of ANOVA in table 6. for the dependent variables demonstrated that the model was significant for all the three response variables [41].

Table 6: Result of ANOVA

\begin{tabular}{llllllll}
\hline Response model & Sum of square & Degree of freedom & Mean square & F value & P value & R square & Ade. precision \\
\hline Floating Lag time & 2.05 & 5 & 0.41 & 9.89 & 0.0045 & 0.8759 & 9.263 \\
\% Drug release & 250.96 & 3 & 83.65 & 3.87 & 0.0496 & 0.9636 & 7.281 \\
\hline
\end{tabular}

From data given in table 6 it can be concluded that as predicted values agreed well with the experimental values, demonstrating the feasibility of the model in the development of floating tablet dosage form.

Table 7: Stability studies of optimized A3 batch

\begin{tabular}{lllll}
\hline Parameters & Hardness $\mathbf{~ K g} / \mathbf{c m} 2)$ & Friability (\%) & Drug content (\%) & Floating lag time (min) \\
\hline Initial & $5.9 \pm 2.1$ & $0.41 \pm 0.00$ & $99.05 \pm 2.51$ & $1.45 \pm 1.8$ \\
After storage & $5.7 \pm 1.8$ & $0.54 \pm 0.41$ & $98.65 \pm 1.04$ & $2.43 \pm 1.2$ \\
\hline
\end{tabular}

${ }^{*}$ All the values are mean \pm SD of three determinations 


\section{Stability study}

Stability study is carried out on an optimized batch (A3) of Bisoprolol fumarate floating tablets. As per table VII the tablet did not show any physical changes during the study period, which is show in table VII and the drug content was found to be $98.65 \pm 1.04 \%$, On the basis of results of the stability study we concluded that Designed formulation was stable after stability study.

\section{CONCLUSION}

In this study, an optimized novel floating tablets of Bisoprolol Fumarate were was successfully prepared by using various polymers such as Polyox N $12 \mathrm{~K}$ and Carbapol 940 P. Developed floating tablet found to be good without chipping, capping characteristics. Hardness or crushing strength of the tablets of all the formulation was found between 5.8 and $6.5 \mathrm{~kg} / \mathrm{cm}^{2}$. Floating lag time of all batches are in range of $1.18 \pm 2.0$ to $2.43 \pm 1.6$ (minutes). The polymer Carbopol $940 \mathrm{P}$ had the significant negative effect of on the floating lag times. The In vitro dissolution profiles of optimized A3 floating formulation of Bisoprolol Fumarate were found to sustain drug release $99.25 \%$ up to $12 \mathrm{~h}$ with floating lag time of 1.45 min. $3^{2}$ full factorial design and optimization technique successfully used in the fabrication of these formulations. Furthermore, developed formulations were stable after stability study. The promising outcomes from the current studies is selected Bisoprolol Fumarate floating tablets could be regarded as a promising gastroretentive drug delivery system that could improve the bioavailability and hence Patient compliance.

\section{ACKNOWLEDGEMENT}

The authors are thankful to Hazrat Maulana G. M Vastanvi Sahab, President, Jamia Islamia Ishaatul Uloom's Ali Allana College of Pharmacy Akkalkuwa, Dist-Nandurbar for providing the Research work facilities.

\section{FUNDING}

Nil

\section{AUTHORS CONTRIBUTIONS}

All the authors have contributed equally.

\section{CONFLICT OF INTERESTS}

Declared none

\section{REFERENCES}

1. Prinderre P, Sauzet C, Fuxen C. Advances in gastro retentive drug-delivery systems. Expert Opin Drug Dev 2011;3:1189-203.

2. Sathiyaraj S, Ramya DD, Vedha BNH. Lornoxicam gastro retentive floating matrix tablets: design and in vitro evaluation. J Adv Pharm Technol Res 2011;2:156-623.

3. Hoffman A, Stepensky D, Lavy E, Eyal S, Klausner E, Friedman M. Pharmacokinetic and pharmacodynamic aspects of gastroretentive dosage forms. Int J Pharm 2004;277:141-53.

4. Padmavathy J, Saravanan D, Rajesh D. Formulation and evaluation of ofloxacin floating tablets using HPMC. Int J Pharm Pharm Sci 2011;3:170-3.

5. Tort S, Han D, Steckl AJ. Self-inflating floating nanofiber membranes for controlled. Drug Delivery Int J Pharma 2020;17:119-64.

6. Arora S, Ali J, Ahuja A, Khar RK, Baboota S. Floating drug delivery system: a review. AAPS PharmSciTech 2005;6:372-90.

7. Narang N. An updated review on: floating drug delivery system. Int J Appl Pharm 2011;3:1-8.

8. Patel DM, Patel NM, Pandya NM, Jogani PD. Formulation and optimization of carbamazepine floating tablets. Indian J Pharm Sci 2007;69:763-70.

9. Auriemma G, Cerciello A, Sansone F, Pinto A, Morello S, Aquino RP. Polysaccharides based gastroretentive system to sustain piroxicam release: development and in vivo prolonged antiinflammatory effect. Int J Bio Macro 2018;120:2303-12.

10. Gokbulut E, Vural I, Așlkoglu M, Ozdemir N. Floating drug delivery system of itraconazole: formulation, in vitro and in vivo studies. J Drug Dev Sci Tech 2019;49:491-501.
11. Baumgartner S, Kristl J, Vrecer F, Vodopivec P, Zorko B. Optimization of floating matrix tablets and evaluation of their gastric residence time. Int J Pharm 2000;195:125-35.

12. Li S, Lin S, Daggy BP, Mirchandani HL, Chien YW. Effect of HPMC and carbopol on the release and floating properties of gastric floating drug delivery system using factorial design. Int J Pharm 2003;253:13-22.

13. Chueh HR, Zia H, Rhodes CT. Optimization of sotalol floating and bioadhesive extended-release tablet formulation. Drug Dev Ind Pharm 1995;21:1725-47.

14. Sathiyaraj S, Ramya DD, Vedha BNH. Lornoxicam gastro retentive floating matrix tablets: design and in vitro evaluation. J Adv Pharm Technol Res 2011;2:156-62.

15. Patil H, Tiwari RV, Repka MA. Recent advancements in mucoadhesive floating drug delivery systems: a mini-review. J Drug Dev Sci Tech 2016;31:65-71.

16. Biswas N, Sahoo RK. Tapioca starch blended alginate mucoadhesive-floating beads for intragastric delivery of metoprolol tartrate. Int J Bio Macro 2016;83:61-70.

17. Jagdale SC, Bari NA, Kuchekar BS, Chabukswar AR. Optimization studies on compression coated floating-pulsatile drug delivery of bisoprolol. BioMed research Int 2013:1-23. https://doi.org/10.1155/2013/801769

18. Latha K, Uhumwangho MU, Sunil SA, Srikanth MV, Ramanmurthy KV. In vitro evaluation of oral timed-release tablet of losartan potassium using natural gum and it's solid characterization. Int J Pharm Pharm Sci 2012;4:89-95.

19. Klausner EA, Lavy E, Friedman M, Hoffman A. Expandable gastroretentive dosage forms.J Controlled Release 2003;90:143-62.

20. Chaturvedi K, Umadevi S, Vaghani S. Floating matrix dosage form for propranolol hydrochloride based on gas formation technique: development and in vitro evaluation. Sci Pharm 2010;78:927-39.

21. Rosa M, Zia H, Rhodes T. Dosing and testing in vitro of a bioadhesive and floating drug delivery system for oral application. Int J Pharm 1994;105:65-70.

22. Dasharath MP, Mehul JP, Ankit NP, Chhagan NP. Formulation and evaluation of mixed matrix gastro-retentive drug delivery for famotidine. Int J Pharm Investig 2011;1:247-54.

23. Kim S, Hwang KM, Park YS, Nguyen TT, Park ES. Preparation and evaluation of non-effervescent gastroretentive tablets containing pregabalin for once-daily administration and dose proportional pharmacokinetics. Int J Pharm 2018;550:160-9.

24. Raza A, Bukhari NI, Karim S, Hafiz MA, Hayat U. Floating tablets of minocycline hydrochloride: formulation, in vitro evaluation and optimization. Future J Pharm Sci 2017;3:131-9.

25. Gambhire MN, Ambade KW, Kurmi SD, Kadam VJ, Jadhav KR. Development and in vitro evaluation of an oral floating matrix tablet formulation of diltiazem hydrochloride. AAPS PharmSciTech 2007;8:E166-E174.

26. Bertram U, Bodmeier R. In situ gelling, bioadhesive nasal inserts for extended drug delivery: in vitro characterization of a new nasal dosage form. Eur J Pharm Sci 2006;27:62-71.

27. Thakar K, Joshi G, Sawant KK. Bioavailability enhancement of baclofen by gastroretentive floating formulation: statistical optimization, in vitro and in vivo pharmacokinetic studies. Drug Dev Ind Pharm 2013;39:880-8.

28. Hwang SJ, Park H, Park K. Gastric retentive drug-delivery system. Crit Rev Ther Drug Carrier Syst 1998;15:243-84.

29. Leung SHS, Robinson JR. The contribution of anionic polymer structural features to mucoadhesion. J Controlled Release 1987;5:223-31.

30. Sharwaree R Hardikar, Shakil S Mulla. Optimization of formulation of solid dispersion of furosemide by factorial design. Int J Pharm Pharm Sci 2020;12:43-8.

31. Nayak AK, Das B, Maji R. Gastroretentive hydrodynamically balanced systems of ofloxacin: in vitro evaluation. Saudi Pharm J 2013;21:113-7.

32. Khan GM, Zhu JB. Studies on drug release kinetics from ibuprofen-carbomer hydrophilic matrix tablets: influence of co-excipients on release rate of the drug. J Controlled Release 1999;57:97-203.

33. Najmuddin M, Shelar S, Ali A, Patel V, Khan T. Formulation and in vitro evaluation of floating microspheres of ketoprofen 
prepared by emulsion solvent diffusion method. Int J Pharm Pharm Sci 2010;2:13-7.

34. Santus G, Lazzarini G, Bottoni G. An in vitro-in vivo investigation of oral bioadhesive controlled release furosemide formulations. Eur J Pharm Biopharm 1997;44:39-52.

35. Pawar VK, Kansal S, Asthana S, Chourasia MK. Industrial perspective of gastroretentive drug delivery systems: physicochemical, biopharmaceutical, technological and regulatory consideration. Expert Opin Drug Delivery 2012;9:551-65.

36. Veerareddy PR, Bajjuri S, Sanka K, Jukanti R, Bandari S, Ajmeru $\mathrm{RK}$, et al. Formulation and evaluation of gastroretentive dosage form of ofloxacin. S J Pharm Sci 2011;4:9-18.

37. Menon A, Ritshel WA, Sakr A. Developement and evaluation of a monolithic floating dosage form for furosemide. J Pharm Sci 1994;83:239-45.
38. Singh B, Chakkal SK, Ahuja N. Formulation and optimization of controlled release mucoadhesive tablets of atenolol using response surface methodology. AAPS PharmSciTech 2006; 7:E19-E28.

39. Vemula SK, Venisetty RK, Veerareddy PR. Valsartan floating bioadhesive compression-coated mini-tablets: formulation and pharmacokinetics. J Drug Dev Sci Tech 2017;40:66-72.

40. Patil P, Rao BS, Kulkarni SV, Basavaraj CS, Ammanage A. Formulation and in vitro evaluation of floating matrix tablets of ofloxacin. Asian J Res Pharm Sci 2011;1:17-22.

41. Singh BM, Kim KH. Floating drug delivery system: an approach to oral controlled drug delivery via gastric retention. J Controlled Release 2000;63:235-59. 